\title{
O Secundarista e o Processo de Escolha da Profissão*
}

\author{
Avia Gusmão Ramos \\ Eliene Rodrigues de Lima \\ Trajeto Consultoria Ltda.
}

Analisa o processo de escolha profissional de secundaristas, alunos da rede pública e particular da cidade de Recife, partindo do relatório da evasão da Universidade do Federal de Pernambuco (UFPE). Apesar da relevância das variáveis apresentadas, esta pesquisa atém-se ao processo de escolha profissional, apoiada na hipótese de que este pode ser um dos pontos de origem deste fenômeno. A amostra constituiu-se de 360 alunos, do segundo e terceiro anos, de nove escolas, divididas em três categorias: tradicional, voltada para o vestibular e pública. Os instrumentos de investigação foram questionários e entrevistas semidirigidas, aplicadas a 10\% da amostra. Para seleção, observou-se os critérios: escola, gênero e ano escolar. Foram realizadas análises estatística e qualitativa dos dados. Esta última foi resultado do conteúdo emergente no discurso, cuja referência teórica foi a Psicanálise. Orientadores e psicólogos, também, foram entrevistados. Os resultados demonstram que estudantes de todas as categorias de escola fazem a escolha profissional com elementos pouco consistentes, enquanto orientadores e psicólogos exercem uma pluralidade de funções que os desviam da sistematização de um trabalho estruturado sobre a Orientação Profissional.

Esta pesquisa analisou o processo de escolha profissional dos secundaristas, alunos de escolas públicas e particulares da cidade de Recife.

*Esta pesquisa contou com a colaboraçẫo do Prof. Mozart Neves Ramos, reitor da Universidade Federal de Pernambuco (UFPE). 
Seu ponto de partida surgiu do fenômeno da evasão constatado nos cursos superiores do Brasil, o qual desperta a atenção das Instituições Federais de Ensino Superior (IFES) e órgãos diretamente vinculados ao Ministério da Educação. Conforme relatório elaborado pela Pró-Reitoria para Assuntos Acadêmicos (1995), o índice de evasão da Universidade Federal de Pernambuco (UFPE) atingiu o porcentual de $34 \%$. Os resultados desse levantamento demonstram que apenas os cursos de Medicina, Direito, Arquitetura e Jornalismo apresentam menores índices de evasão (Anexo I).

Segundo o professor Mozart Neves (1993), esse fato é preocupante, inclusive, porque o custo anual do aluno das instituições de ensino superior das redes federal, estadual ou municipal é de dez mil dólares. $\mathrm{O}$ aluno que se evade, portanto, onera a sociedade e não lhe oferece nenhum retorno.

Alguns fatores foram considerados responsáveis pela evasão: a necessidade de o discente trabalhai- devido a sua condição financeira, a restrição do mercado de trabalho, os índices de reprovação nos primeiros anos de universidade, principalmente nos cursos com alto índice de matematicidade, o processo de seleção do vestibular etc.

Segundo a visão do Ministério da Educação, o índice de evasão se constitui um dos indicadores utilizados para a avaliação qualitativa das Instituições de Ensino Superior do país. No entanto, instituições que se destacam pela qualidade do ensino, como é o caso da USP e Unicamp, apresentam um índice médio de evasão relativamente alto (40\%).

É possível que a evasão esteja relacionada a uma multiplicidade de variáveis. Esta pesquisa, porém, ateve-se ao processo de escolha profissional apoiada na hipótese de que este pode ser um dos seus pontos de origem. Neste sentido, questiona o nível de conscientização dos alunos e se os obstáculos que impulsionam o abandono dos cursos não seriam melhor administrados caso houvesse uma posição mais clara sobre essa escolha.

Ao escolher uma profissão, o adolescente está, também, definindo o seu projeto de vida e, como tal, o modo de conquistar sua autonomia, seu reconhecimento pessoal e sua participação na sociedade através do trabalho. 
Esse momento, no entanto, tem sido alvo de pouco investimento por parte dos pais, da escola e da sociedade, os quais, freqüentemente, percebem a universidade como um fim em si mesma. Trata-se a classificação no concurso do vestibular como o objetivo maior desse percurso, em detrimento da viabilidade do projeto profissional e, do mesmo modo, das repercussões pessoais e sociais de uma escolha dessa natureza.

\section{Metodologia}

A análise do processo de escolha profissional dos secundaristas foi realizada a partir dos dados obtidos através de 360 sujeitos pertencentes a nove escolas da cidade de Recife, divididas em três categorias: tradicional, voltada para o vestibular e pública.

Foi considerada tradicional a escola que privilegia a transmissão de conhecimentos gerais, a avaliação padronizada e comparativa através de notas, o controle explícito das atitudes e comportamentos, dedicando pouca atenção às características individuais (Nicolaci-da-Costa, 1986, p.37).

Por escola voltada para o vestibular entende-se um sistema de ensino que dá ênfase aos assuntos e matérias exigidos neste concurso, oferecendo material didático próprio, aulas de revisão e plantões específicos para garantir o melhor desempenho antes e durante o vestibular.

A escola pública tem por característica básica ser subsidiada pelo governo, sem fins lucrativos.

Os instrumentos de investigação foram os seguintes: a) Questionários aplicados a 360 sujeitos, contendo dez questões ao todo, das quais, oito foram questões fechadas e duas abertas. Estes dados foram submetidos a tratamento estatístico: a um teste não paramétrico para verificação de diferenças em tabelas cruzadas com dados nominais - o qui-quadrado - e o levantamento freqüencial simples (Anexo H). 
b) Entrevistas - entrevistas semidirigidas aplicadas a 10\% da amostra, cujo objetivo foi fornecer dados à análise qualitativa realizada através do método dialético do discurso o qual privilegia o sentido implícito existente nas contradições e no conteúdo simbólico da fala do sujeito (Anexo HI).

\section{UNIVERSO DA AMOSTRA}

Constituiu-se de 360 sujeitos dos segundo e terceiro anos com a finalidade de investigar a escolha em curso ou já efetivada pela aproximação do vestibular. Foi realizada uma distribuição equitativa desses sujeitos nas três categorias de escola.

Em cada categoria foram escolhidas três escolas, cujo universo de alunos apresentassem, dentro do mesmo grupo, níveis socioeconómicos distintos, considerando-se que o nível socioeconômico pudesse ser uma variável relevante.

\section{PROCEDIMENTO}

A coleta de dados da pesquisa obedeceu às seguintes fases:

Fase 1. Aplicação dos questionários - foi realizada de modo coletivo em cada escola. A escolha dos sujeitos foi aleatória, obedecendo ao número de matrícula, ao critério de gênero e ano escolar.

Fase 2. Realização das entrevistas - para garantir a uniformidade do procedimento, os pesquisadores foram treinados previamente. As entrevistas foram realizadas individualmente com sujeitos escolhidos de modo aleatório dentro do universo da amostra, observando-se a proporcionalidade dos critérios de escola, gênero e ano de escolaridade.

Fase 3. Entrevistas com orientadores educacionais ou psicólogos de cada escola - realizadas a partir de três questões, que tiveram como objetivo conhecer a operacionalização do processo de escolha profissional, quais sejam:

O que entende por escolha profissional?

Quais são os meios utilizados para assessorar o jovem nesse processo? Quais são os efeitos do trabalho desenvolvido? 


\section{Resultados}

POSIÇÃO DOS ALUNOS DIANTE DA ESCOLHA PROFISSIONAL

Os dados obtidos a partir das entrevistas apontam a tendência dos estudantes da cidade de Recife, tanto da rede pública, quanto da rede privada, a fazer a escolha profissional apoiada em elementos pouco consistentes (vide Quadro 1). Comumente alienados ao projeto familiar - seja para dar continuidade, fazer diferente ou ajudar na subsistência da família - ,os adolescentes, em especial os da rede privada, iniciam um curso universitário com informações mínimas (vide Quadro 2) e sem discriminar seus interesses, aptidões, as próprias expectativas e as expectativas da família (Quadro 1).

\section{Quadrol - Fatores determinantes da escolha profissional N (36)}

1. Desejo da família. $80,56 \%$

1.1. Escolha para atender apenas ao desejo da família, sem que o jovem se aperceba dessa posição $36,11 \%$

1.2. Escolha para garantir a inserção no mercado de trabalho devido à influência ou ao patrimônio da família $19,44 \%$

1.3. Escolha para atender às expectativas da família, embora o jovem perceba que seu próprio desejo é diferente $11,11 \%$

1.4. Escolha sob pressão familiar $8,33 \%$

2. Escolha por identificação a alguma pessoa significativa. $11,11 \%$

3. Escolha com base na identificação do próprio jovem com a profissão

Observa-se que o projeto da família está na matriz da escolha profissional aparecendo de modo expressivo e determinante, seja no campo do desejo (itens 1.1,1.3 e 1.4 do Quadro 1) ou apoiado numa justificativa social, por exemplo, as escolhas pela garantia do mercado de trabalho (item 1.2 do Quadro 1). 
Considera-se um bom nível de informações quando o jovem dispõe de conhecimento sobre as atividades profissionais, campos de atuação, função social, condições do mercado de trabalho, viabilidade de retomo financeiro, identificação das características pessoais necessárias ao exercício da profissão.

\section{Quadro 2 - Informações sobre as profissões N (36)}

1. Ausência de informações $36,11 \%$

2. Informações estereotipadas $19,44 \%$

3. Informações gerais sobre as atividades da profissão. $16,67 \%$

4. Informações sobre o cotidiano da profissão através dos familiares $13,90 \%$

5. Idealização da profissão. $8,33 \%$

6. Bom nível de informações. $5,55 \%$

Conforme o resultado das entrevistas demonstrado no quadro acima, apenas 5,55\% dos secundaristas encontram-se nessa condição, enquanto a maioria, num total de 58,34\% (vide itens 2,3,4,5 e 6 do Quadro 2) dos jovens possuem um conhecimento restrito a estereótipos, a algumas atividades da profissão, às experiências dos familiares ou a idealizações.

\section{RESPOSTAS DAS ENTREVISTAS X RESPOSTAS DOS QUESTIONÁRIOS}

Durante as entrevistas, os jovens foram estimulados a refletir e a explicitar as respostas dadas no questionário. Os dados fornecidos demonstram informações desintegradas, distorcidas e inconsistentes, resultando numa aparente contradição entre os dois instrumentos utilizados, conforme será discutido adiante.

Quadro 3 - Posição do jovem diante da escolha profissional N (360)

Escolheram a profissão $60,8 \%$

Consideram-se em dúvida ..................................................................... 32,8\%

Não escolheram a profissão... $6,4 \%$ 
Quadro 4 - Posição dos alunos que escolheram a profissão N (218)

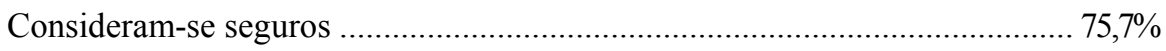

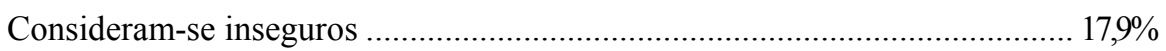

Escolheram a profissão sem pensar ........................................................... 5,5\%

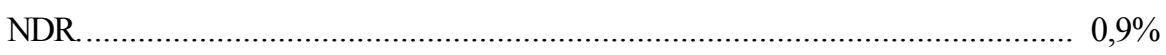

Quadro 5 - Informação sobre as profissões a partir dos questionários N (360)

Atividades da profissão

Quadro 6 - Fatores que interferem na escolha profissional N (360)

Interesse pelas atividades da profissão........................................................ 75,8\%

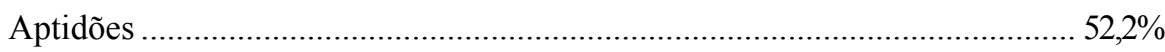

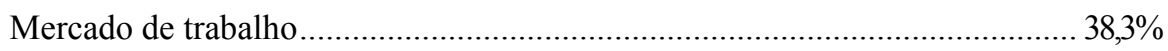

Profissionais que admiram..................................................................... 33,9\%

Matérias exigidas para o vestibular........................................................... 31,4\%

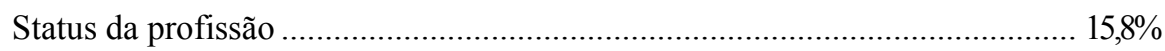

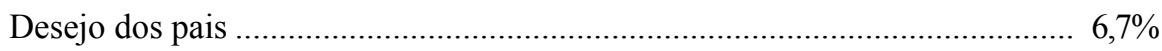

Através destes dados, delineia-se um porcentual significativo de jovens que escolheram a profissão (Quadro 3), que se sentem seguros (Quadro 4) e que afirmam possuir um razoável nível de informações (Quadro 5), além de conhecer os diversos fatores que interferem na escolha profissional (Quadro 6). Chama a atenção, ainda, o modo como a interferência do desejo da família é minimizada (Quadro 6). 
Não é surpreendente a diferença existente entre o resultado dos questionários e das entrevistas. É natural que o adolescente sinta dificuldade em discriminar suas posições das posições da família, dos amigos, dos professores, dos grupos aos quais pertence.

Nesta etapa do desenvolvimento, caracterizada pela passagem da infầncia à vida adulta, está em jogo uma série de mudanças necessárias à conquista da independência emocional e econômica dos pais, a definição sexual, a construção de uma nova identidade, um novo modo de pensar, novos interesses, motivações, desejos... A autonomia e a responsabilidade pelos próprios atos e escolhas são conquistas desejadas e temidas ao mesmo tempo. Essas mudanças, inclusive, não ocorrem sem conflitos para os adolescentes nem para os pais.

Diante desse transcurso, o adolescente se defende desqualificando a influência, os valores e a dependência dos pais, negando os conflitos, incertezas, aferrando-se a fantasias de onipotência e a idealizações.

Do lado dos pais, a adolescência dos filhos remete à sua própria, com todas as facilidades e as dificuldades vivenciadas. Coincide com a idade em que estão perdendo a juventude, estão questionando suas vidas, suas escolhas e, dentre as escolhas, suas profissões. A escolha profissional de um filho, nesta perspectiva, representa uma retomada da própria escolha com todas as conseqüências e, do mesmo modo, representa o confronto com os projetos e as expectativas que possuem em relação ao filho, os quais traduzem e expressam o seu desejo.

Segundo a psicanálise, é no campo do desejo que o ser humano se estrutura. $\mathrm{O}$ desejo se inscreve na dimensão do inconsciente produzindo comportamentos, atitudes, contradições, escolhas, projetos, expectativas que escapam ao domínio da consciência. Escapam ao explícito, às aparências. Em tudo o que o homem faz estão implícitos os efeitos de um outro sentido, o sentido que existe no inconsciente. A dimensão do inconsciente responderá sempre pela impossibilidade de o ser humano assegurar e conhecer tudo sobre si mesmo, sobre o que deseja, sobre o que escolhe.

Nesta perspectiva, podem-se entender as aparentes contradições existentes entre os resultados dos questionários e das entrevistas. Os questionários 
solicitam respostas imediatas que expressam as idéias conscientes que o sujeito possui sobre si mesmo, com todas as defesas contra a dúvida, a inquietação, a incerteza. As entrevistas instigam a reflexão discursiva sobre essas respostas imediatas, deste modo, aparecem na fala do sujeito lapsos, falhas e contradições que constituem as aberturas para a emergência de um outro sentido existente no inconsciente sobre o próprio desejo e sobre as marcas do desejo da família, embora sejam, freqüentemente, desconhecidos.

\section{POSIÇÃO DAS ESCOLAS DIANTE DA ESCOLHA PROFISSIONAL}

Conforme o exposto, entende-se que a escolha profissional é um processo complexo, no qual o adolescente necessita de assessoria para refletir e integrar uma multiplicidade de fatores - objetivos e subjetivos - que intervém nessa decisão.

$\mathrm{O}$ quadro a seguir demonstra os meios a que os jovens recorrem para fazer a escolha de sua profissão.

\section{Quadro 7 - Principais meios utilizados pelos jovens para a escolha da profissão}

\begin{tabular}{|c|}
\hline 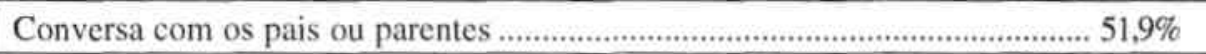 \\
\hline 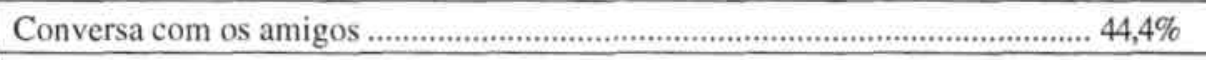 \\
\hline 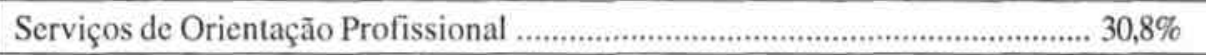 \\
\hline 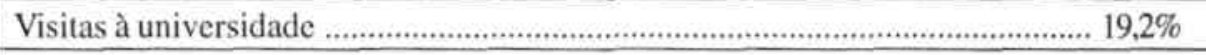 \\
\hline 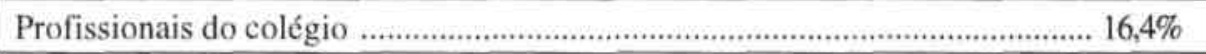 \\
\hline Outros meios \\
\hline 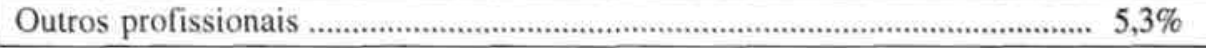 \\
\hline Revistas e similares ..................................... \\
\hline
\end{tabular}

Observa-se que os próprios jovens procuram com mais intensidade meios não especializados - família e amigos. Os serviços especializados, como a orientação profissional, visitas à universidade, profissionais do colégio, revistas e similares são recursos pouco utilizados. Neste sentido, não estaria este fato interligado à posição da escola diante do processo de escolha profissional? 
Deve-se atentar para o fato de que a utilização preponderante dos meios não especializados não permite que o adolescente obtenha informações com a neutralidade necessária à discriminação e ao reconhecimento dos seus projetos e do projeto dos pais ou da família. O seguinte fragmento do discurso de um dos sujeitos explicita seu aprisionamento nesta problemática, ao se referir a uma profissão, no caso, jornalismo, como se fosse medicina, sem se aperceber desse fato: "Vou fazer medicina, porque desde pequena eu gosto de inventar, criar estórias, fazer redação, escrever...Meus pais se desesperam se eu fizer jornalismo, dizem que vou ser sustentada pelo marido".

É natural que as informações fornecidas pelas pessoas envolvidas emocionalmente tenham o peso do seu desejo, dos seus projetos. Que a família não perceba suas implicações, entende-se. A escola, entretanto, tem a responsabilidade de tratar esse tema sob outra perspectiva.

Ausentando-se da função de subsidiar e conscientizar o jovem sobre a importância da escolha profissional, a escola os aliena. Esses estudantes não têm noção das repercussões que esta escolha poderá ter para sua vida no que se refere à possibilidade de a profissão se constituir num campo para o seu reconhecimento pessoal através do mundo do trabalho, num campo de produção, de contribuição social, de aquisição de sua autonomia financeira ou, ao contrário, num campo de fracasso e sentimento de incompetência quando não se sabe o porquê dessa escolha.

\section{POSIÇÃO DIANTE DA ESCOLHA PROFISSIONAL POR CATEGORIA DE ESCOLA}

As escolas da rede pública e privada assumem posições diferentes diante da escolha profissional. Enquanto a escola pública não atribui maior relevância a essa questão, a escola privada, segundo depoimento dos seus orientadores e psicólogos escolares, incentiva os alunos do segundo grau a pensarem na profissão, em especial, às vésperas do vestibular, e sem oferecerem muitos subsídios.

Neste sentido, a escola particular confere ao vestibular e à universidade o estatuto de um fim em si mesmos, inclusive, dando ênfase à concorrência, 
conforme se evidencia no gráfico abaixo. Observa-se que um elevado índice de alunos da rede privada consideram a concorrência do vestibular a maior dificuldade de sua escolha profissional (51,7\% dos alunos das escolas tradicionais, e $56,7 \%$ das escolas voltadas para o vestibular).

Atribuir à concorrência do vestibular a condição de maior dificuldade do processo de escolha profissional é desfocar o essencial dessa questão, ou seja, é minimizar a importância de uma escolha consistente em prol da simples aprovação no vestibular.

Segundo o teste qui-quadrado para tabelas quadradas, a probabilidade de que a diferença apresentada se dê ao acaso é $\mathrm{p}<.01$.

Este fato, possivelmente, está ligado a uma das distorções do sistema educacional brasileiro - o concurso do vestibular. A proximidade do vestibular leva a escola a exigir, e os alunos a executar a escolha pelos núcleos de saúde, humanas e exatas enquanto determinações formais. Quais são as conseqüências de uma escolha apoiada nessas bases?

De acordo com o gráfico acima, aproximadamente $30 \%$ dos alunos das escolas particulares - 30\% das escolas tradicionais e 29,2\% das escolas voltadas para o vestibular- reclamam da falta de informações.

$\mathrm{Na}$ escola pública, a carência de informações é ainda mais evidente, aparecendo como principal dificuldade para 40,3\% dos jovens (vide Gráfico 1 ). Vale ressaltar que essa desinformação não se restringe apenas às profissões universitárias, ela é extensiva às profissões técnicas. Diante desta situação, o que cada escola tem feito?

Observa-se que as escolas costumam tratar a escolha profissional apenas pelo viés informativo. Os alunos das escolas tradicionais dispõem de informações sobre alguns aspectos das profissões, especialmente sobre atividades profissionais $(78,3 \%)$, mercado de trabalho $(69,2 \%)$, matérias de peso para o vestibular $(65,8 \%)$, onde fazer os cursos $(50 \%)$, perfil profissional $(45,8 \%)$ e salário (45\%).

Os alunos das escolas voltadas para o vestibular dispõem de informações restritas a três aspectos: atividade da profissão $(63,3 \%)$, mercado de trabalho $(58,3 \%)$ e matérias de peso para o vestibular $(44,2 \%)$. 
Quanto à escola pública, a desinformação predomina sobre quase todos os aspectos, exceto as atividades profissionais que são conhecidas por 44,2\% desse universo.

Novamente, o teste qui-quadrado para tabelas quadradas aponta que a probabilidade que essas diferenças se dêem por acaso é $\mathrm{p}<.01$.

Considerando este resultado, pode-se afirmar que os alunos das escolas tradicionais representam a categoria de escola que mais dispõe de informação sobre as profissões. Possivelmente, pelo fato de a referida categoria privilegiar a transmissão de conhecimentos de modo mais abrangente, no entanto, não atribui o devido peso ao processo de escolha profissional.

Quanto à restrição das informações dos alunos das escolas voltadas para o vestibular, pode ser resultante da ênfase que é dada a este concurso.

\section{POSIÇÃO DOS ORIENTADORES E PSICÓLOGOS}

Os dados constatam que a escola demanda a esses profissionais uma pluralidade de funções que comprometem a sistematização de um trabalho estruturado sobre a escolha profissional. Segundo o depoimento deles, suas funções incluem desde o atendimento dos pais e adolescentes por motivos diversos, a substituição dos professores em sala de aula, até o planejamento de horário de estudos para alunos dispersivos. Esta posição reflete a menor importância que a escola atribui a este tema. Freqüentemente, os trabalhos sobre a escolha profissional se restringem aos alunos que admitem de modo explícito suas dúvidas ou inseguranças. E, conforme já foi dito, como o adolescente tende a negar conflitos e incertezas, as escolhas da maioria resultam em opções pouco consistentes.

\section{Considerações finais}

A escolha profissional é um processo complexo que faz parte de um projeto de vida, o qual demanda a integração de uma multiplicidade de fatores de ordem econômica, política, social e psicológica. No que se refere a este último aspecto, a Trajeto Consultoria constata, através desta pesquisa, o que já 
observara em sua prática, ou seja, que a matriz da escolha profissional encontrase no desejo dos pais. É na relação com os pais que um filho é reconhecido como aquele que poderá corresponder às maiores expectativas ou aquele de quem não se espera muito.

As marcas do reconhecimento aparecem no processo de escolha profissional quando, no primeiro caso, apesar da credibilidade dos pais, o excesso de exigências ou a não identificação do adolescente com o projeto familiar produzem uma inércia, mesmo quando as informações obtidas já seriam suficientes para sua escolha. No segundo caso, quando não se tem expectativas em relação ao filho, a problemática é mais preocupante, porque a repercussão para o adolescente se expressa na posição de descrédito em si próprio, expresso através do sentimento de que "não dá pra nada" ou de que só poderá escolher profissões desvalorizadas socialmente.

Tais posições não são consideradas a partir de um julgamento de valor, mas da concepção de que das malhas do desejo não é possível fugir. O desejo, segundo a Psicanálise, estrutura as relações entre pais e filhos, formula pedidos, age e mesmo quando é desconhecido, se interpõe, obscurecendo a decisão.

Quanto aos fatores objetivos, é de fundamental importância cuidar da qualidade das informações no sentido de contextualizar as profissões e, deste modo, evitar distorções, estereótipos e idealizações.

No tocante à escola, a atenção ao processo de escolha tem sido basicamente no segundo grau, restringindo-se às informações sobre as profissões, em especial, nas escolas particulares. Nesta categoria de escola, a ênfase recai sobre o vestibular em detrimento da qualidade da escolha.

A escola pública não oferece alternativa de escolhas por profissões universitárias nem técnicas. Além do desinvestimento nestas duas direções, a realidade socioeconómica da maioria dos seus alunos se impõe produzindo um corte em sua trajetória estudantil, quando os lança no mercado de trabalho sem qualificação profissional. Segundo Castro (1994, p.38-39), a maior deserção nas escolas públicas acontece a partir da quarta série do primeiro grau, atingindo um índice de 18,4\%. Esses alunos permanecem, em média, oito anos na escola pública e só conseguem chegar à quinta série. Isto porque, continua o autor, 
navegam muito lentamente dentro do sistema chegando a acumular, pelo menos, três repetências. Esta situação demonstra que o sistema educacional, enquanto alicerce ideológico do país, não oferece saídas para as profundas desigualdades sociais.

Neste sentido, vale retomar o papel que a escola brasileira vem historicamente assumindo em tomo da educação e da profissionalização. Catani et ai. ( 1989, p.213-214) relatam que a dicotomia educar versus profissionalizar é antiga no Brasil. Enquanto a educação era reservada aos ricos, a preocupação com a inserção no mercado de trabalho destinava-se aos pobres, o que significava que o acesso à universidade era caminho exclusivo daqueles que tinham recursos. Na década de 50, com o processo de industrialização, essa dicotomia começou a ser repensada. No entanto, as diversas tentativas para conciliar os objetivos de educar e profissionalizar foram feitas através de decretos e leis. Deste modo, os efeitos não foram sentidos, visto que o caráter classista e seletivo do ensino decorre da estrutura socioeconómica do país e não se elimina com tais medidas.

Os referidos autores (idem, p.215-218) afirmam que essa dicotomia perde sentido quando se considera que a função da escola não é preparar para o mercado de trabalho e sim, para o mundo de trabalho. O compromisso da escola é com a formação do trabalhador, com o exercício da cidadania e não apenas com o exercício de uma profissão.

Nesta perspectiva, o mundo do mibalho é um princípio educativo e função da escola. Para o aluno ser introduzido nesse campo, necessita:

a) uma base sólida de formação geral, humanística e científica (um bom ensino de Português, Geografia, História, Filosofia, Matemática, Física, Química e Biologia);

b) conhecer e desenvolver a consciência do significado do trabalho, sua evolução, suas produções no contexto da crescente complexidade dos diferentes sistemas ideológicos e das diferentes sociedades;

c) ter conhecimento sobre a organização do mercado de trabalho local, regional e nacional; salário, políticas salariais; direitos e deveres do trabalhador. 
A preparação para o mundo do trabalho pode ter a participação da escola antes, durante e depois da profissionalização. Esta última, porém, é função específica das empresas.

Seguindo esta linha de raciocinio, os autores (idem, p.218) afirmam que o trabalho como principio educativo não pode ser uma mera aprendizagem formal, teórica e intelectualizada. Ao contrario, há de ser uma reflexão orientada por todos os professores, todo o pessoal administrativo, técnico e auxiliar, a partir da experiência vivida pelos alunos no trabalho desenvolvido dentro e fora da escola. Enquanto lugar de trabalho, e a partir de sua própria realidade, a escola pode envolver toda a instituição, além da família e da comunidade. Assim, os conhecimentos gerais e científicos adquirem vida, agilidade e criatividade condições que poderão ser utilizadas, posteriormente, no mercado de trabalho.

Para que os alunos adquiram essas condições, os professores também necessitam de preparo para aliar à especificidade de sua formação reflexões sobre o mundo do trabalho que sejam integradas ao contexto de suas disciplinas.

A realidade é que a escola não tem conseguido tratar o mundo do trabalho em sua dimensão de princípio educativo e, do mesmo modo, não tem conseguido tratar a escolha profissional como parte integrante dele. Ou seja, como um processo que acompanha toda a trajetória estudantil. Enquanto processo, deve ser indicado no primeiro grau, pois será estruturado através do desenvolvimento da capacidade de pensar, investigar, duvidar, criticar.

Estas são condições fundamentais para o aluno elaborar conteúdos pedagógicos de modo participativo, assumindo posições diante dos temas estudados, identificando as áreas do conhecimento humano que mais the interessam. Nestas condições, alicerça-se a capacidade de refletir, integrar, avaliar a relação existente entre os conhecimentos teóricos e a vida prática, alicerça-se a capacidade de fazer escolhas, dentre as quais se encontra a escolha da profissão.

O aluno, contudo, não é convidado a exercer uma posição ativa no processo de ensino-aprendizagem. Não é estimulado a fazer articulações entre as matérias que estuda e suas aplicações no mundo do trabalho. Essa desintegração gera uma aprendizagem meramente teórica, tendo como ponto central a figura do professor, enquanto o aluno tende a decorar apenas o que the 
foi transmitido. Impede-se, desta forma, a emergência da curiosidade, da investigação, da dúvida - pontos de origem da construção do saber e do senso crítico.

Os reflexos do modelo de ensino vigente aparecem no desestímulo das crianças e dos adolescentes, os quais associam a necessidade de estudar a uma simples obrigação. Os adolescentes, em especial, apresentam um sentimento de incompetência e de descrédito na própria capacidade de pensar. É evidente que estas marcas dificultam o processo de escolha profissional e o desempenho de uma profissão.

Como já ficou explícito, no processo de escolha da profissão é fundamental que se considere a família, a escola e a sociedade como agentes implicados, cuja importância é proporcional ao fato de que são segmentos que podem estruturar e determinar a posição do indivíduo na vida.

Para nortear os comentários sobre os efeitos integrados desses três segmentos, os estudos de Sérvulo Figueira (1986) nos oferecem valiosa contribuição por terem analisado as mudanças ocorridas na sociedade brasileira e suas repercussões na família e na escola. Por conseguinte, pode-se pensar que essas mudanças interferem, também, no modo como os pais e os educadores se posicionam diante da escolha profissional dos jovens.

Preocupado com os efeitos do chamado processo de modernização de nossa sociedade, Figueira (ibid., p. 15-17) estudou as referidas gerações, tendo como uma de suas referências teóricas a Psicanálise. Para ele, a família da década de 50 era hierárquica, pois se definia pelo modo de organização que mapeava e demarcava nitidamente as diferenças existentes entre homem/mulher, adulto/ criança, pais/filhos, professor/aluno. Essas diferenças eram visíveis através da roupa, da linguagem, do comportamento, do exercício do poder do homem sobre a mulher, do adulto sobre a criança, dos pais sobre os filhos, dos professores sobre os alunos. O ideal hierárquico foi progressivamente abandonado em prol da ideologia de igualitarismo que, de acordo com o referido autor, causou o maior impacto na família, além das várias causas sociais e políticas que também estão subjacentes a esse processo. 
Na década de 80, a família passou a ser igualitária. Caracterizava-se por sua identidade idiossincrática: homem/mulher, adulto/criança/adolescente são iguais enquanto indivíduos e, portanto, possuem os mesmos direitos. A diferença percebida era apenas no que diz respeito às singularidades pessoais. Isto significa dizer que o igualitarismo diluiu as fronteiras que delimitavam as diferenças de sexo, idade e posições.

Figueira (1986, p.24-29) entende que a modernização seria resultante de um processo lento de elaboração interna de novos valores, os quais passariam a integrar o comportamento do sujeito. $\mathrm{O}$ autor chama a atenção para o fato de o ser humano não ter condições de se desvencilhar dos valores antigos que estão internalizados com a mesma velocidade que pode assimilar mudanças sociais de outra natureza. De acordo com sua concepção, o que ocorreu foi muito mais um processo de modernização reativa ou falsa modernização.

A modernização reativa caracteriza-se por um descompasso entre os valores antigos e os modernos. Este descompasso impulsiona um desmapeamento, impulsiona comportamentos pautados numa dissociação entre os referidos valores.

Acontece que os valores antigos ou arcaicos - como são considerados - continuam presentes de modo invisível - inconsciente - mas, com uma força atuante que se contrapõe à imposição dos valores modernos.

A exemplo, pode-se observar que o casal da família igualitária é formado por filhos da família tradicional. Na tentativa de negar os ideais e valores de sua família de origem, confundem autoritarismo com autoridade, perdem a condição de estabelecer os limites, de proibir, de impor a lei. Em outras palavras, na ilusão do igualitarismo, os pais da nova familia se retiram do lugar de referência para as crianças e para os adolescentes.

Com base nos estudos de Figueira (ibid., p. 18-20), pode-se afirmar que a sociedade permanece, cada vez mais, inibindo o pensamento hierárquico - considerado arcaico - enquanto investe no que se chama processo de modernização. Um dos discursos responsáveis pela ilusão de que as diferenças não existem é sustentado pelo psicologismo fundamentado nas distorções dos conceitos psicanalíticos difundidos através da mídia e do cotidiano da população. 
Em nome dessa "concepção teórica", para evitar "traumas", crianças e adolescentes são tratados como se pudessem fazer o que desejam. O resultado disto é a instalação de um clima de permissividade e de negação das diferenças que impede os pais, os professores e demais figuras de autoridade de estabelecerem os limites, a lei. Elemento esmaturante da vida em sociedade, a lei impõe fronteiras; discrimina a diferença dos lugares dos pais/filhos, adulto/ crianças, homem/mulher, professor/aluno; permite que as figuras de autoridade assumam seu lugar de referência.

Como se pode constatar, a coexistência da ideologia arcaica e da ideologia moderna é responsável pela oscilação dos pais frente aos filhos -ora são liberais, ora extremamente rígidos e radicais ou completamente omissos. Essas mesmas posições se expressam no momento da escolha profissional dos adolescentes: proíbem ou exigem a continuidade do projeto profissional da família e/ou se omitem em nome da "liberdade de escolha".

Que os pais atribuam à escolha profissional do filho o peso do seu próprio desejo, de suas experiências, ou que se omitam, é esperado. A escola, porém, tem a função de convocá-los a refletir sobre o papel fundamental que possuem no sentido de facilitar a assunção do desejo do filho em direção a determinados campos profissionais, ao invés de se omitirem ou de o aprisionarem num projeto familiar que pode não coincidir com seus interesses, potencialidades e aptidões. E assim, é função da escola tratar das implicações pessoais e sociais da escolha profissional no mundo do trabalho.

Da mesma forma que os pais, por força dos mesmos efeitos do processo de modernização, os educadores se encontram divididos entre o modelo da escola tradicional e o ideal igualitário da escola vanguardista. Com o intuito de atender à demanda da família igualitária, surgiu a escola vanguardista com projetos pedagógicos individualizantes destinados ao pré-escolar e aos primeiros estágios do período escolar propriamente dito. Estas propostas, fomentadas pelo processo de psicologização da sociedade, davam realce ao reconhecimento do indivíduo e ao desenvolvimento de suas potencialidades em detrimento da ênfase na sistematização teórica - preocupação básica da escola tradicional. Além dos efeitos das distorções da modernização reativa, os educadores, e, em especial, 
os professores estão sendo penalizados através do descaso reinante com a educação no país. Apesar de serem figuras de peso, enquanto referência, se encontram desestimulados, desempenhando, na escola, atividades estritamente necessárias ao exercício de suas tarefas. Neste aspecto, pode-se perguntar quais são as conseqüências para a formação do aluno, para sua noção do mundo do trabalho, para a escolha e para o exercício de uma profissão.

Conforme o exposto, a importância do processo de escolha profissional exige uma reflexão por parte da escola, da sociedade e da família. Algumas alternativas seriam possíveis para reverter esta situação:

a) tratar a escolha da profissão enquanto processo e iniciá-la no primeiro grau;

b) capacitar os professores do primeiro e segundo graus para subsidiar o aluno no processo de escolha profissional inserido na visão do mundo do trabalho em sua dimensão educativa;

c) sistematizar programas de orientação profissional que permitam ao adolescente integrar à sua escolha a multiplicidade de elementos que aí se encontram em jogo;

d) estruturar programas específicos para os diferentes níveis de escolaridade (primeiro e segundo graus) e as diferentes realidades de escolas (públicas e privadas);

e) oferecer palestras e orientação aos pais no sentido de introduzi-los nesse processo;

f) promover amplo debate com a sociedade, objetivando despertar a atenção para a importância da escolha profissional e de suas repercussões para o país;

g) desenvolver ações conjuntas que promovam a integração entre o segundo grau e a universidade: disponibilidade, por parte dos departamentos dos vários Centros, em oferecer informações aos alunos do segundo grau; promoção de palestras e debates sobre a realidade das profissões; elaboração do material informativo sobre as profissões técnicas e universitárias.

Vale salientar que as conseqüências da trajetória do estudante explodem na universidade, dentre elas, a ausência de ações mais consistentes das escolas 
do primeiro e segundo graus sobre o processo de escolha da profissão. Mais grave, ainda, é a situação dos estudantes que, além de não terem perspectivas de chegar à universidade deixam a escola em condições precárias de inserção no mercado de trabalho.

\section{Referências bibliográficas}

CASTRO, CM. Educação brasileira: consertos e remendos. Rio de Janeiro: Rocco, 1994.

CATANI, A.M. et ai. Ensino do segundo grau e mercado de trabalho. Revista Brasileira de Estudos Pedagógicos, Brasília, v.70, n. 165, p.208-223, maio/ ago. 1989.

AS CAUSAS da evasão dos alunos dos cursos de graduação do Centro de Tecnologia da UFPE. [Recife]: Centro de Tecnologia [da] UFPE, 1992. Questionário.

FIGUEIRA, S.A. (Org.). Uma nova família?: o moderno e o arcaico na família de classe média brasileira. Rio de Janeiro: Zahar, 1986.

NICOLACI-DA-COSTA, A.M. Família e pedagogia: nostalgia do tradicional ou carência do novo? In: FIGUEIRA, S.A. (Org.). Uma novafamília?: o moderno e o arcaico na família de classe média brasileira. Rio de Janeiro: Zahar, 1986.

RAMOS, M.N. Quadro da evasão na UFPE. Pró-Reitoria para Assuntos Acadêmicos/UFPE. Recife: Universitária, 1993.

. Quadro de evasão na UFPE: metodologia, causas e ações. Pró-Reitoria para assuntos Acadêmicos/UFPE. Recife: Universitária, 1995. 
Sílvia Gusmão Ramos e Eliene Rodrigues de Lima, especialistas em Psicologia Clínica pela Universidade Federal de Pernambuco (UFPE), são diretoras da Trajeto Consultoria, instituição de pesquisa e assessoria em Orientação Profissional, em Recife-PE.

This research analyzed high school students ' process of professional choice - students from private and public schools in Recife - based on the report on drop-out in the Universidade Federal de Pernambuco. Despite of the relevance of the variables put forward, the research concentrated on the process of professional choice, supported by the hypothesis that this process might be at the origin of this phenomenon. The sample included 360 students from the second and third year (second grade of the Brazilian high school system), in nine schools, divided in three categories: the traditional one, the one which prepares for the "vestibular" (Brazilian university entrance examination) and the public one. The data included: questionnaires and partly guided interviews applied to $10 \%$ of the sample. As for the selection, the following criteria were observed: school, sex and academic year. The data were analyzed statistically and qualitatively. The latter analysis was based on the emerging content from the interviews, and psychoanalysis served as a theoretical background. Supervisors and psychologists were also interviewed. The results revealed that the students in all school categories make a professional choice with very little consistent elements, while the supervisors and psychologists have a varied and large number of tasks preventing them from having a systematization of a well structured work on professional advisory system.

Cette recherche a analysé le processus du choix que font les lycéens de leur métier. Ces lycéens appartiennent au réseau public et particulier de la ville de Recife. Nous nous sommes basés sur le rapport qui montre l'évasion de V Universidade Federal de Pernambuco. Malgré l'importance des variables présentées, cette recherche $n$ 'a analysé que le processus de choix d'un métier et s'est basée sur l'hypothèse que ce processus peut être 
/ 'un des points d'origine de ce phénomène. L'échantillon était constitué de 360 élèves de deuxième et troisième années de neuf écoles divisées en trois catégories: traditionnelle, tournée vers le baccalauréat et publique. Nos instruments d'investigations ont été les suivants: des questionnaires et des entrevues semi-dirigées, appliqués à 10\% de l'échantillon. Pour la selection on a observé les critères suivants: école, genre et année scolaire. On a effectué des analyses statistiques et qualitatives des données. Ces dernières ont été le résultat du contenu émergeant dans le discours dont la référence théorique a été la Psychanalyse. Des orienteurs et des psychologues ont été interviewés aussi. Les résultats démontrent que des lycéens de toutes les catégories d'école font le choix de leur métier basés sur des éléments peu consistants alors que les orienteurs et les psychologues exercent une pluralité de fonctions qui les dévient de la systématisation d'un travail structuré sur l'orientation professionnelle.

Esta pesquisa analiso el proceso de elección profesional de alumnos de liceo de la red pública y particular de la ciudad de Recife. Partió del informe de la evasión de la Universidade Federal de Pernambuco. Apesar de la importancia de las variables presentadas, esta pesquisa se basó en el proceso de elección profesional y en la hipótesis de que éste puede ser uno de los puntos de origen de éste fenómeno. La muestra se constituyó de 360 alumnos del segundo y del tercer año de nueve escuelas divididas en tres categorías: tradicional, volcada para el Bachirellato y pública. Los instrumentos de investigación fueron questionários y entrevistas aplicadas a 10\% de la muestra. Para selección, obervamos los critérios siguientes: escuela, género y año escolar. Estas últimas fueron resultado del contenido que inmergió en el discurso cuya referencia teórica fue la Psicoanálisis. Orientadores y psicólogos fueron también entrevistados. Los resultados demostraron que los alumnos de todas las categorías de escuela elijen su profesión con elementos poco consistentes, mientras orientadores y psicólogos ejercen una pluralidad de funciones que los desvían de la sistematización de un trabajo estructurado sobre la orientación profesional. 


\section{Anexos}

\begin{tabular}{|c|c|}
\hline Taxa de & $\%)^{*}$ \\
\hline Curso & Taxa de evasão ( \% ) \\
\hline Serviço Social & 48 \\
\hline Secretariado & 42 \\
\hline Pedagogia & 35 \\
\hline Historia & 47 \\
\hline Geografía & 45 \\
\hline Ciencias Sociais & 55 \\
\hline Filosofia & 71 \\
\hline Administração & 19 \\
\hline Ciencias Contábeis & 23 \\
\hline Economia & 38 \\
\hline Direito & 9 \\
\hline \multicolumn{2}{|l|}{ Areai } \\
\hline Engenharia Civil & 42 \\
\hline Engenharia Química & 42 \\
\hline Engenharia Mecânica & 41 \\
\hline Engenharia Eletrônica & 36 \\
\hline Engenharia Eletrotécnica & 41 \\
\hline Engenharia de Minas & 62 \\
\hline Engenharia Cartográfica & 68 \\
\hline Bacharelado em Química & 45 \\
\hline Bacharelado em Física & 50 \\
\hline Bacharelado em Matemática & 67 \\
\hline Estatística & 64 \\
\hline
\end{tabular}




\begin{tabular}{|c|c|}
\hline Ciência da Computação & 17 \\
\hline \multicolumn{2}{|l|}{ Área II } \\
\hline Medicina & 8 \\
\hline Farmácia & 32 \\
\hline Nutrição & 58 \\
\hline Odontologia & 22 \\
\hline Fisioterapia & 30 \\
\hline Terapia Ocupacional & 51 \\
\hline Educação Física & 42 \\
\hline Psicologia & 24 \\
\hline Enfermagem & 56 \\
\hline Ciências Biomédicas & 50 \\
\hline Ciências Biológicas & 63 \\
\hline \multicolumn{2}{|l|}{ Área III } \\
\hline Arquitetura & 11 \\
\hline Letras & 40 \\
\hline Biblioteconomia & 43 \\
\hline Artes Plásticas & 29 \\
\hline Artes Cênicas & 62 \\
\hline Projeto Produto & 45 \\
\hline Programação Visual & 31 \\
\hline Licenciatura Desenho & 58 \\
\hline Jornalismo & 13 \\
\hline Publicidade & 29 \\
\hline Radial ismo & 39 \\
\hline Licenciatura Música & 39 \\
\hline \multicolumn{2}{|l|}{ Área IV } \\
\hline UFPE & 34 \\
\hline
\end{tabular}


Questionário

Data:

DADOS DE IDENTIFICAÇÃO

Nome: (iniciais)

Idade:

Ano escolar:

Colégio:

Sexo:

Profissão do pai ou responsável:

Profissão da mãe:

1. Você já escolheu sua profisssão?
() $\mathrm{Sim}$
( )Não
() Em dúvida ()NDA

2. Que profissão você pensou no processo de escolha?

3. Qual a profissão escolhida?

1

4. Em relação a sua escolha, você considera-se: ( ) Inseguro ( ) Seguro ( ) Não pensou no assunto ( ) NDA

5. Como você conheceu a profissão escolhida ou de seu interesse ( ) Através dos amigos ( ) Através dos professores ( ) Através dos familiares ( ) Através dos pais

( ) Através dos profissionais que você admira ( )

Outras pessoas ( )NDA 
6. Quais são as informações que você dispõe sobre a(s) profissão(ões)

que lhe interessa(m) ouquejáescolheu? ( )

Mercado de trabalho ( ) Atividades da

profissão ( ) Onde estudar ( ) Salário

( ) Disciplinas do curso ( ) Matérias de

peso para o vestibular ( ) Características

dos profissionais

( ) Outras:

( )NDA

7. Quais são os meios utilizados para a escolha da profissão?

( ) Serviços de orientação profissional

() Visitas a universidades

() Profissionais de seu colégio

( ) Conversas com os pais ou parentes

( ) Conversas com amigos

() Profissionais

() Revistas

( ) Outros:

( ) Nenhuma

8. Indique os fatores que influenciam na escolha de sua profissão:

( ) Aptidão para exercer a profissão

( ) Interesse pelas atividades da profissão

( ) Profissionais que você admira

( ) Possuir informações apenas sobre a profissão escolhida

( ) O status da profissão

( ) Mercado de trabalho

( ) Atender ao desejo dos pais ou da família 
( ) Possibilidade de maior retorno financeiro

( ) Curso menos concorrido

( ) Afinidade com as matérias exigidas para o vestibular

() Outros:

( )NDA

9. Quais as dificuldades encontradas na escolha? ( ) Falta de informações

( ) Não reconhecer seus interesses e aptidões ( ) Medo de não corresponder às expectativas dos pais ou da familia ( ) Grande concorrência para o vestibular ( ) Restrição do mercado de trabalho ( ) Matérias exigidas para o vestibular

( ) Outras:

( ) Nenhuma

10.0 que você espera conseguir na universidade?

11.0 que você pensa conseguir na profissão? 


\section{ANEXO III Questões para \\ entrevista com os adolescentes \\ Verificar ocupação e profissão dos pais $\mathbf{1 . 0}$ que}

é escolher uma profissão?

2. O que o atrai nas profissões que lhe interessam ou que você já escolheu (falar o que o atrai em cada profissão individualmente)?

3.0 que lhe dá segurança ou insegurança no processo de escolha profissional (quais os elementos que asseguram a certeza ou a incerteza, internamente)?

4. Qual é a relação existente entre o seu jeito de ser e a(s) profissão(ões) de seu interesse ou de sua escolha?

5. O que você sabe sobre os cursos que pretende?

6. O que você sabe sobre a prática profissional (considere as facilidades e as dificuldades do exercício da profissão)? 
7. Quais as profissões das pessoas significativas?

8. Quais são as profissões valorizadas pela família?

9. Como é para você escolher uma profissão igual ou diferente desses valores?

10. Quais foram os recursos utilizados na orientação vocacional que ajudaram ou confundiram sua escolha (esta questão só deve ser feita para quem se submeteu à orientação)? Identifique o momento e os elementos.

11. Dentre os recursos utilizados por você para a escolha da profissão, quais foram os elementos que ajudaram e os que dificultaram? (esta questão deve ser feita para quem não se submeteu à orientação). 